\title{
VAREJO ONLINE: ESTUDO DOS ESTÍMULOS DAATMOSFERA DE LOJA À LUZ DE EROGLU
}

\author{
ON LINE RETAILING: STUDY OF THE STIMULUS \\ OF ATMOSPHERE STORE ACCORDING TO EROGLU
}

\author{
Josemeire Alves Gomes ${ }^{1}$, Alexandre Ramos de Moura ${ }^{2}$, \\ Jane Costa de Menezes ${ }^{3}$, Polyana Karina Mendes Ximenes ${ }^{4}$ e \\ Danielle Miranda de Oliveira Arruda ${ }^{5}$
}

Recebido em: 07/01/2014 Aprovado em: 23/07/2014

\section{RESUMO}

A pesquisa de Kotler, desenvolvida em 1973, representa um marco do início dos estudos sobre os efeitos da atmosfera de loja no comportamento de compra do consumidor. Mais recentemente, com o crescimento do varejo on-line, a atmosfera da loja virtual também vem sendo estudada, principalmente por meio de comparações com as lojas físicas. Diante disso, este artigo teve como objetivo analisar de que modo os estímulos presentes na atmosfera de loja são desenvolvidos pelos supermercados sediados no ambiente virtual. Para tanto, adotaram-se os estímulos da atmosfera de loja propostos por Eroglu et al. (2001), classificados como ambiente de tarefa altamente relevante e de baixa relevância. O método utilizado foi a observação não participante, e a coleta de dados ocorreu nos websites de oito supermercados localizados no território brasileiro. Os resultados demonstram que os supermercados desenvolvem mais efetivamente os estímulos do ambiente diretamente relacionados ao fechamento da compra. Este estudo reforça, assim, a literatura sobre atmosfera de loja virtual ao descrever como os estímulos que influenciam os consumidores a dar uma reposta de compra são desenvolvidos, contribuindo para sua melhor compreensão. Do ponto de vista gerencial, pode fornecer diretrizes para os empresários obterem melhores resultados com as vendas nos supermercados virtuais.

Palavras-chave: Varejo on-line; Atmosfera de loja virtual; Supermercado virtual; Estímulos do ambiente.

\begin{abstract}
Kotler's research, developed in 1973, is a landmark of the early studies on the effects of store atmosphere on consumer buying behavior. More recently, with the growth of online retailing, the atmosphere of the virtual store is also being studied, especially by comparison with physical stores. This article aims to analyze how the stimuli present in the atmosphere of the store are made by supermarkets based in the virtual environment. The stimuli of the atmosphere store proposed by Eroglu et al. (2001), classified as highly relevant task and low environmental relevance were adopted. The method used was a non-participant observation and data collection was performed in the websites of eight supermarkets located in the brazilian territory. The results show that supermarkets develop more effectively the environmental stimuli directly related to the closing of the purchase. Finally, this study reinforces the literature on virtual store atmosphere to describe how the stimuli that influence consumers to make a purchase response are developed, contributing to a better understanding. From a managerial perspective, the study can provide guidelines for managers get better results with sales in virtual supermarkerts.
\end{abstract}

Keywords: On-line retailing; Atmosphere of virtual store; Virtual supermarket; Environmental stimuli.

\footnotetext{
'Doutoranda em Administração pela Universidade de Fortaleza (UNIFOR), Brasil. E-mail: josemeire.gomes@gmail.com. ${ }^{2}$ Mestrando em Administração pela Universidade de Fortaleza (UNIFOR), Brasil. E-mail: alexandreramosmoura@hotmail.com. ${ }^{3}$ Mestranda em Administração pela Universidade de Fortaleza (UNIFOR), Brasil. E-mail: jane_menezes@hotmail.com. ${ }^{4}$ Doutoranda em Administração pela Universidade de Fortaleza (UNIFOR), Brasil. E-mail: polyanaximenes@gmail.com. ${ }_{5}^{5}$ Doutora em Administração pela Université de Nice, França. Professora de Marketing no Programa de Pós-Graduação em Administração da Universidade de Fortaleza (UNIFOR), Brasil. E-mail: danielle@unifor.br.
} 


\section{Introdução}

O início do século XXI caracterizou-se pelo surgimento e desenvolvimento do comércio eletrônico, que criou uma nova forma de comercialização de bens e serviços por meio do ambiente virtual, denominada de varejo on-line. A compreensão do processo de decisão de compra nesse ambiente e de seus impactos no comportamento do consumidor criou uma nova linha de estudos na área de marketing. Elementos como as motivações para a compra, o risco percebido na segurança e privacidade das informações, a satisfação, a compra por impulso e a atmosfera da loja virtual caracterizam as principais vertentes propostas nesses estudos.

A pesquisa de Kotler, desenvolvida em 1973, marcou o início do interesse de pesquisadores pelo estudo da influência da atmosfera de loja no comportamento do consumidor. De acordo com Turley e Milliman (2000), foi Kotler quem primeiro definiu o termo atmosfera, embora outros pesquisadores tenham previamente manipulado elementos do ambiente. Em seu artigo, Kotler (1973) define atmosfera como os esforços para desenhar ambientes de compra capazes de produzir efeitos emocionais específicos no comprador, de modo a aumentar suas probabilidades de compra. Estudos como os de Bitner (1990, 1992), Donavan et al. (1994), Turley e Millliman (2000), Baker et al. (2002), Carvalho e Motta (2002), Espinoza, D'Angelo e Liberali (2005), Sampaio et al. (2009) e Feijó e Botelho (2012) indicam a atmosfera de loja como grande influenciadora na decisão do consumidor em escolher uma loja, podendo seu planejamento eficaz fazer a diferença entre o sucesso e o fracasso do negócio.

A atmosfera da loja física é composta, segundo Bitner (1992), por três dimensões principais que influenciam o comportamento do consumidor: o design, o social e o ambiente. O design refere-se a aspectos essencialmente visuais, como o layout e as cores. A dimensão social, por sua vez, está relacionada aos funcionários no ponto de venda. Já $\mathrm{o}$ ambiente relaciona-se às condições que afetam os cinco sentidos humanos, as quais tendem a ser especialmente percebidas quando se apresentam em situações extremas, como, por exemplo, quando as pessoas são submetidas ao estímulo de músicas excessivamente altas ou temperaturas extremamente baixas; quando os indivíduos permanecem no ambiente por muito tempo ou quando ocorre uma discrepância no que tange às suas expectativas. Como o ambiente virtual não apresenta todas as características do ambiente de um varejo tradicional, embora apresente outras diferentes como a flexibilidade no tempo e espaço, a atmosfera de loja desempenha um papel preponderante no processo de decisão de compra, podendo gerar aproximação ou afastamento do comprador (EROGLU et al., 2001).

Diante do exposto, verifica-se a importância de aprofundar o estudo acerca das características da atmosfera da loja virtual que podem influenciar o comportamento do consumidor. Assim, a questão que norteia este trabalho é: como são desenvolvidos os estímulos do ambiente da atmosfera de loja virtual? Para tanto, foram escolhidos como objeto de estudo os supermercados sediados em ambiente virtual devido à sua importância para o varejo e o cenário econômico brasileiro.

Portanto, o objetivo geral deste trabalho é analisar como são desenvolvidos os estímulos do ambiente presentes na atmosfera dos supermercados virtuais sediados no ambiente on-line. Para atender a esse objetivo, foi utilizado o modelo conceitual de Eroglu et al. (2001), com o intuito de compreender, especificamente, de que forma os estímulos do ambiente de tarefa altamente relevante e do ambiente de tarefa de baixa relevância são aplicados pelos supermercados virtuais. Neste estudo, o conceito de estí- 
mulo adotado é o de Eroglu et al. (2001), que definem estímulo como a soma de todas as sugestões que são visíveis e audíveis para o comprador on-line. A suposição é de que, se os estímulos forem desenvolvidos de maneira adequada, a resposta do comprador consistirá na aproximação, o que geraria um aumento da receita de vendas.

Dessa forma, o estudo da atmosfera de loja e de suas características fazse importante para identificar elementos que possibilitem o aperfeiçoamento dos estímulos do ambiente dos supermercados virtuais praticados até o presente momento, de maneira a resultar em um comportamento de aproximação maior de seus compradores, melhorando, consequentemente, sua lucratividade e competitividade. Quanto à contribuição teórica, este estudo permite enriquecer os conceitos sobre atmosfera de loja virtual, com base na revisão de literatura e na observação nas organizações estudadas. Quanto à contribuição prática, possibilita contribuir com gestores, empresários e pesquisadores interessados em saber como obter resultados mais eficazes por meio de uma atmosfera de loja adequada aos seus perfis de negócios e consumidores.

Este artigo está estruturado em cinco partes, além desta introdução. A seguir, apresenta-se o referencial teórico que trata de supermercado virtual, da atmosfera de loja virtual e do detalhamento do modelo adotado. A seção três apresenta o método de pesquisa utilizado. Já a seção 4 expõe a discussão dos resultados. Por fim, na quinta seção, seguem as considerações finais.

\section{Referencial teórico}

\subsection{Supermercado virtual}

Considerado um dos mais importantes representantes do varejo tradicional, o setor supermercadista brasileiro faturou, segundo a Abras (2013), no ano de 2012, R\$ 243 bilhões, elevando suas vendas reais em $2,3 \%$ em relação ao ano de 2011. A participação do setor no Produto Interno Bruto (PIB) brasileiro chega à $5,5 \%$, caracterizando um canal de distribuição de alimentos expressivo para a economia brasileira.

Em virtude dessa grande importância e ao não alheamento à evolução do varejo on-line e ao perfil dos novos consumidores, o comércio eletrônico também foi inserido no cotidiano dessas organizações, fazendo surgir os denominados supermercados virtuais. A entrega de alimentos na porta do consumidor, por exemplo, não é algo recente, e muitos supermercados já ofereciam este serviço por décadas antes do surgimento do comércio eletrônico (MURPHY, 2007). A diferença é que agora o tempo desperdiçado pelos consumidores e os aborrecimentos com linhas de telefone ou fax congestionadas com muitos pedidos foram contornados por meio da internet. Ainda segundo o mesmo autor, um supermercado virtual pode oferecer um número de itens ainda maior do que uma grande loja a um custo menor, o que possibilita atingir um volume de vendas mais elevado e ganhar em economia de escala.

No Brasil, o sistema de comercialização de produtos por meio de supermercado virtual teve o Zona Sul Atende, sediado no Rio de Janeiro, como pioneiro (MOREIRA, 2008). Posteriormente, foram lançados o Sendas e o Market Delivery. Quanto ao contexto no qual surgiu esse tipo de varejo, Cutieri e Donaire (2000, p. 2) afirmam que ele "emerge em um ambiente em que a evolução tecnológica e as mudanças no perfil do consumidor, principalmente no que tange ao tempo disponível para ir às compras, são consideradas tendências favoráveis ao processo de compra eletrônica".

Alguns estudos empíricos contribuíram para o avanço do conhecimento nessa área. Como exemplos, pode-se citar: Cutieri e Donaire (2000), que analisaram o perfil do consumidor, 
os aspectos valorizados e criticados no relacionamento virtual e as motivações para a compra on-line; Graeml et al. (2000), que buscaram identificar as impressões de um grupo de pessoas usuárias de internet sobre o seu primeiro contato com o serviço de comércio eletrônico no supermercado; Lerner (2003), que estudou como os clientes avaliam a qualidade dos serviços prestados pelos supermercados do Rio de Janeiro e a maneira como os supermercados definem a política de qualidade de serviço; Hijjar (2006), que examinou a qualidade do serviço prestado pelos supermercados virtuais sob a ótica das percepções e expectativas dos clientes, e Moreira (2008), que buscou descrever e analisar o processo de decisão de compra dos consumidores no supermercado virtual.

\subsection{Atmosfera de loja virtual}

O impacto da atmosfera da loja física no comportamento do consumidor foi demonstrado em diferentes áreas de estudo, como em marketing e psicologia. O crescimento do varejo on-line levou pesquisadores a considerarem a influência da atmosfera da loja no contexto de compra virtual, bem como se os princípios da atmosfera de loja física podem ser aplicados à loja virtual, ao estabelecerem analogias e comparações entre elas (FLOH; MADLBERGER, 2013). Em um desses estudos, Lohse e Spiller (1999) identificaram aspectos da loja física, como layout, promoções, serviços e merchandising, e desenvolveram características correspondentes para as virtuais, demonstrando que a interface do site é essencial para estabelecer um relacionamento com o consumidor. Após a análise de diversos trabalhos, Manganari et al. (2009) concluíram que, embora as pesquisas sobre a atmosfera da loja virtual ainda sejam um campo de estudo relativamente novo, existe uma evidência empírica do seu impacto sob diferentes aspectos do comportamento do consumidor.

Como o ambiente da loja virtual apresenta diferenças fundamentais em relação às lojas físicas, que podem dar ênfase ao layout, ao merchandising, a luzes, à sinalização, a cores e a cheiros, as atividades de marketing e comportamento do consumidor precisam ser reavaliadas nesse contexto (HOFFMAN, NOVAK, 1996; MUMMALANENI, 2005). De acordo com Alba et al. (1997), três aspectos são notadamente diferentes entre os dois contextos de loja: na loja virtual, o campo de visão do consumidor é muito mais estreito do que ao andar por uma grande loja, pois limita-se a uma pequena tela; a distância e o tempo são menores; e o controle dos consumidores em relação às informações que buscam e aos sites que desejam visitar é maior.

Nessa mesma perspectiva, Burke et al. (1992) afirmam que esses consumidores tendem a focar imediatamente em itens particulares, e, como o tempo é mais curto, os itens avistados primeiro tendem a satisfazer mais que os itens vistos depois. Além disso, como na loja virtual os consumidores assumem o controle do seu próprio caminho, provavelmente uma nova variável da atmosfera de loja que pode influenciar o comportamento de compra seja a sequência de produtos ou websites que o consumidor encontra durante uma simples experiência de compra (MENON; KAHN, 2002). As autoras propõem que as características encontradas inicialmente nos produtos ou websites visitados influenciam o nível de satisfação na experiência de compra e, posteriormente, a escolha de websites e o comportamento de compra. Para tanto, desenvolveram um conjunto de categorias de efeito no comportamento de compra que variam com as características dos produtos ou experiências que o consumidor encontra inicialmente em um website.

Manganari et al. (2009), por sua vez, propuseram um modelo conceitual de layout de loja virtual, enfatizando 
que a experiência de compra também deve ser transferida ao ambiente virtual por meio do desenvolvimento da habilidade por parte dos varejistas de transmitirem ao comprador o sentimento de estar em uma loja física. Para os autores, a manipulação eficaz do layout e da atmosfera da loja virtual representa uma ferramenta de marketing estratégica, que pode vir a contribuir na eficácia e diferenciação por meio da determinação dos estados internos e das respostas dos consumidores.

Nessa mesma perspectiva, Chen et al. (2010) realizaram um estudo em uma amostra de 1.567 respondentes com o objetivo de identificar a lista de atributos dos websites das lojas virtuais que influenciam o comportamento do consumidor, aumentando sua intenção de compra. Os autores identificaram que as características do ambiente que se relacionam a detalhes da transação, como segurança, privacidade, conveniência e políticas de devolução e trocas de produtos, foram as variáveis mais apontadas pelos entrevistados. Em um outro estudo, Floh e Madlberger (2013) analisaram os efeitos da atmosfera da loja virtual em uma amostra de 508 respondentes, concluindo que os estímulos do ambiente definidos como o design e a navegação eficaz apresentaram os efeitos positivos mais significativos no comportamento do consumidor. Wu et al. (2014) também identificaram, em um estudo composto de uma amostra de 626 respondentes, que o design do layout da loja tem um impacto significativo nas emoções e atitudes dos consumidores em relação ao website.

Outros autores também contribuíram com estudos sobre essa temática, tais como: Ranaganathan e Ganapathy (2002), que analisaram quatro dimensões da atmosfera do site que impactam a intenção de compra dos consumidores (conteúdo da informação, design, segurança e privacidade); Liu e Arnett (2000), cuja pesquisa analisou os sites de grandes empresas e identificou quatro fatores críticos para o seu sucesso (qualidade da informação e serviço, uso do sistema, aspectos lúdicos e qualidade do design); Kim e Stoel (2004), que examinaram a importância da qualidade da atmosfera do site e quais fatores influenciam a satisfação de compra de roupas femininas; Szymanski e Hise (2000), que analisaram como as dimensões conveniência, merchandising, design do site e segurança influenciam a avaliação e satisfação do consumidor em relação à loja virtual, estudo que foi posteriormente replicado por Evanschitzky et al. (2004); Daily (2004), que analisaram como e porquê os consumidores são influenciados pelas sugestões de navegação do site e McKinney (2004), que realizou um estudo para identificar as variáveis da atmosfera que contribuem para a satisfação dos compradores de lojas virtuais.

No campo das publicações brasileiras, Farias (2005) investigou de que maneira o ambiente on-line influencia as emoções do comprador e o impacto das emoções na satisfação e atitude de compra; Kovacs e Barbosa (2005) analisaram a influência da atmosfera da loja virtual na satisfação com o processo de compra e nos riscos percebidos; Costa e Larán (2006) examinaram a relação entre a atmosfera de loja e a compra por impulso, comparando lojas físicas e virtuais; e Gualhanone et al. (2011) verificaram a possibilidade de replicar o ambiente físico da loja de marcas de luxo do mercado brasileiro, sem a perda da aura de requinte e sofisticação da marca.

\subsection{Modelo teórico}

Considerando-se que as características da atmosfera das lojas físicas não se aplicam totalmente às lojas virtuais, Eroglu et al. (2001) desenvolveram um modelo específico para estas. Como o referido modelo constitui o marco teórico deste trabalho, será analisado separadamente nesta seção. 
No ambiente virtual, a habilidade de apelar para os sentidos dos compradores limita-se a aspectos predominantemente visuais, que ocorrem por meio de um monitor. De acordo com o modelo de Eroglu et. al (2001), descrito na Figura 1, a atmosfera da loja virtual é composta por elementos retratados na tela do computador do comprador, de modo que os estímulos influenciam seu estado interno afetivo e cognitivo, resultando em uma resposta de aproximação ou afastamento na experiência de compra.

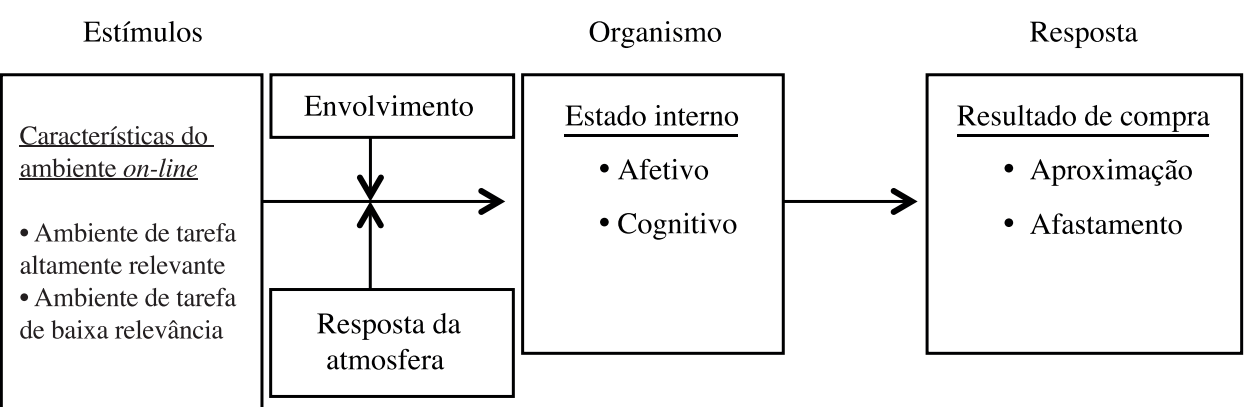

Figura 1 - Modelo S-O-R de resposta do consumidor na compra on-line Fonte: Elaborado pelo autores a partir de Eroglu et al. (2001).

Nesse modelo, os estímulos, que correspondem às características do ambiente da loja virtual, são agrupados em duas categorias: ambiente de tarefa altamente relevante e ambiente de tarefa de baixa relevância. Os elementos do ambiente de tarefa altamente relevante são todos os elementos de descrição de site (verbal ou pictorial) que surgem na tela para facilitar e possibilitar o alcance dos objetivos dos consumidores, incluindo o conteúdo verbal relacionado à tarefa de compra (descrição dos produtos, preço, entrega e política de devolução), fotos dos produtos, disponibilidade de amostras, avaliação dos produtos e ferramentas de navegação (mapa do site e barras de navegação na parte superior ou inferior da página). Já os elementos do ambiente de baixa relevância representam as informações do site que têm pouca influência para concluir a tarefa de compra, englobando conteúdos verbais não relacionados aos objetivos de compra, como cores, bordas, tipos de fonte, padrões de fundo, animações, música e sons, entretenimento (jogos ou concursos), quantidade de espaços em branco, ícones, imagem de mapas, outras figuras com o propósito de deco- ração, indicadores de conexões e transações seguras, webcounter, unidade do site, premiações e símbolos de filiações profissionais.

$\mathrm{O}$ organismo é representado pelos estados internos afetivo e cognitivo, os quais intervêm na relação entre os estímulos do ambiente e a resposta do consumidor. De acordo com os autores, a maioria dos trabalhos de psicologia ambiental foca o organismo nas dimensões do prazer, da excitação e do domínio, sendo este, para o contexto da compra on-line, a resposta emocional mais relevante. Dessa forma, é possível que o comprador prefira a compra on-line em detrimento da compra tradicional, porque as chances de domínio sobre a situação de compra são maiores. No entanto, essas chances se tornam menores quando os downloads estão lentos, quando não existe oportunidade de trocar maiores informações com o varejista, quando é difícil navegar pelo site ou quando os links estão perdidos ou inativos. Entre os estímulos e o organismo existem os moderadores, que compreendem o envolvimento e a resposta da atmosfera. $\mathrm{O}$ primeiro refere-se ao quanto a compra on-line é percebida pelo consumi- 
dor como importante para a realização de seus objetivos, enquanto a resposta da atmosfera corresponde à capacidade que as características do ambiente têm de influenciar as decisões do consumidores sobre onde, como e quanto tempo disponibilizar para as compras. A resposta ao estímulo, caracterizada pelo comportamento de aproximação ou afastamento do comprador, depende, segundo os autores, do ambiente de loja percebido e dos efeitos de mediação entre os traços do próprio indivíduo e o seu estado interno.

Ao focar de maneira específica os estímulos que compõem o ambiente da atmosfera de loja virtual que podem influenciar o comportamento de compra do consumidor, este modelo permite enumerar e analisar detalhadamente esse conjunto de informações do ambiente, sendo, portanto, o mais adequado aos objetivos desta pesquisa. Ressalta-se que, neste estudo, será analisada apenas a primeira parte do modelo, composta pelos estímulos do ambiente. Embora sejam apresentadas outras dimensões, como estado afetivo e cognitivo internos e resposta de aproximação ou afastamento do consumidor, como Eroglu et al. (2001) sugerem, antes de analisar o impacto da atmosfera da loja virtual no comportamento do consumidor, deve ser realizada uma análise de todos os potenciais estímulos do ambiente representados no modelo.

\section{Método}

No presente trabalho, utilizou-se como método de análise dos estímulos da atmosfera dos supermercados virtuais a observação não participante, que é método qualitativo concebido especificamente para o pesquisador apreender aparências, eventos ou comportamentos relacionados aos objetivos da pesquisa (GODOY, 1995). Conforme a autora, a observação não participante se caracteriza pelo envolvimento do pesquisador apenas no nível de espectador atento, que, baseado nos objetivos da pesquisa e no roteiro de observação, faz incursões no seu objeto de estudo, procurando identificar e registrar o máximo de ocorrências relacionadas à sua pesquisa.

A primeira fase desta pesquisa englobou, assim, uma análise exploratória na qual foram mapeados os supermercados que realizam vendas pela internet. Por meio de pesquisa feita em sites de busca, inicialmente, identificaram-se sites de supermercados. Na sequência, procedeu-se a uma visita ao site, analisando se a loja realizava vendas pela internet. Após essa fase, foram identificados oito supermercados que, no período de desenvolvimento deste estudo, atuam no ambiente virtual por meio da venda direta e entrega de produtos ao consumidor, todos localizados em território brasileiro. Optou-se por preservar a identidade dos supermercados, denominando-os doravante de $\mathrm{S} 1$, S2, S3, S4, S5, S6, S7 e S8. Ressalta-se que todos os dados analisados se encontram disponibilizados publicamente nos websites das empresas pesquisadas.

Posteriormente, a partir da revisão da literatura, elaborou-se um roteiro dos estímulos a serem observados, que padronizou a observação dos pesquisadores. O roteiro foi elaborado com base na descrição dos estímulos do ambiente da loja virtual realizada no modelo teórico escolhido para o estudo. Dessa forma, leu-se a descrição dos estímulos a fim de elencar no roteiro o conjunto de observações a serem realizadas pelos pesquisadores. O roteiro divide-se em duas partes, compostas pelos estímulos do ambiente de tarefa altamente relevante e pelos estímulos do ambiente de tarefa de baixa relevância.

A pesquisa foi realizada no decorrer dos meses de maio e junho de 2013, quando foram feitas, em média, 20 visitas aos sites dos supermercados por dois pesquisadores simultaneamente. Nesses sites, foram observados aspectos como a descrição das mercadorias vendidas, a disponibilização e a estrutura da lista de 
compras, as formas de divulgação dos preços, as formas de pagamento, a política de entrega em domicílio e de devolução de produtos, a qualidade das fotos dos produtos, a avaliação dos produtos, as ferramentas de auxílio à navegação, as cores, as bordas, os tipos de fontes e padrões de fundo utilizados, os recursos de animação e entretenimento, os ícones e mapas de imagem, a presença de outros tipos de fotos, os indicadores de conexões e transações seguras, o webcounter e premiações e os símbolos de filiações profissionais.

Ficou estabelecido que todos os estímulos observados deveriam estar disponíveis aos consumidores, sem a obrigatoriedade da realização de pedido ou compra, por dois motivos: o acesso aos estímulos podem implicar a decisão de realizar ou não o pedido ou a compra na loja devido à importância de algumas informações, como condições de entrega, pagamento e devolução; os supermercados analisados estão localizados em diferentes regiões do Brasil, o que impossibilitou os pesquisadores de realizarem pedidos ou compra, uma vez que as lojas só entregam em endereços próximos à sua área geográfica.

Após a coleta dos dados, realizou-se a comparação dos roteiros observados pelos pesquisadores. Para alguns estímulos, fez-se necessário o retorno aos sites e novas observações com o intuito de sanar as dúvidas. Em seguida, procedeu-se à análise dos dados por meio da descrição de como os elementos do ambiente encontram-se desenvolvidos nos websites das empresas estudadas. A seguir, apresenta-se a análise realizada.

\section{Apresentação e discussão dos resul- tados}

O primeiro conjunto de elementos analisados são os que se relacionam ao ambiente de tarefa altamente relevante. Dessa forma, inicialmente, identificou-se como as mercadorias vendidas estão descritas, com número de unidades contidas na embalagem, nome do fabricante e características da composição do produto. Para alguns produtos, são disponibilizados o número do telefone do fabricante e, no caso de gênero alimentício, a tabela nutricional. Nesse item, dois supermercados se destacaram, S3 e S8, pois seus produtos são apresentados com riqueza de detalhes. As mercadorias apresentam fotos, maior quantidade de informação sobre o produto e fabricante e forma de apresentação e quantidade de calorias por porção, sendo separadas por seções para uma maior comodidade do consumidor que realiza sua primeira visita. Os demais supermercados apresentam suas mercadorias com superficialidade de detalhes, o que dificulta a aquisição ou até mesmo a desistência dos compradores que buscam obter maiores detalhes acerca dos produtos antes de realizarem a compra. Ressalta-se, assim, que a falta de riqueza de detalhes na descrição dos produtos anunciados podem provocar uma resposta de afastamento do consumidor, pois, de acordo com Menon e Kahn (2002), as características encontradas nos produtos anunciados têm forte influência no nível de satisfação da experiência de compra.

Após, foi analisado se o supermercado disponibiliza uma lista de compras e de que maneira esta se encontra elaborada. Observou-se, também, se existe diferenciação nas unidades $(\mathrm{kg}$, $\mathrm{L}, \mathrm{g})$ e se há um histórico de compras já realizadas anteriormente pelo consumidor. Na maioria dos supermercados analisados, a lista de compras é dividida por seções, havendo outra divisão por categorias e o histórico de compras, com exceção do S5, que não disponibiliza esse recurso ao consumidor. No S2, são disponibilizadas "lista prontas", classificadas por temas a fim de reunir determinados produtos relacionados ao tema em questão. No S3, o consumidor pode definir os itens de sua lista de compras, bem como seções e cate- 
gorias, por faixa de preço. No S7, além dos fatores mencionados anteriormente, o consumidor também pode realizar suas compras classificando os produtos por ordem de visualização, mais vendidos e similares. Já no S8, é possível ordenar os produtos da lista por marcas, tipos de apresentação e embalagem.

Em relação à forma como os supermercados virtuais divulgam os preços dos seus produtos e à presença de destaques na página para chamar a atenção do comprador, percebeu-se que a maioria atua de forma bastante semelhante, pois apresenta seus produtos com preços divulgados por meio de fontes de pequena visualização, com pouco destaque. A exceção é o S6, que, além de disponibilizar o preço em fonte grande, permite destacá-lo ao clicar sobre o produto.

As formas de pagamento estão disponíveis em todos os supermercados analisados de forma objetiva e de fácil compreensão; porém, alguns o fazem de maneira bastante detalhada, sem permitir dúvidas ao consumidor. Todos aceitam dinheiro, cheque e cartões de débito/crédito de diversas bandeiras. Os supermercados S2, S4 e S6 aceitam também boleto bancário e vale alimentação. O S8 é o único a aceitar pagamento parcelado. Os supermercados S3 e S5, por sua vez, aceitam exclusivamente cartões de débito/crédito. Somente o S1 apresenta um diferencial, disponibilizando um cartão de compras próprio.

Quanto à política de entrega em domicílio, todos os supermercados apresentam, na página principal do site, a área geográfica abrangida, as diferentes taxas cobradas de acordo com a região da entrega e os horários disponíveis. Essa preocupação está de acordo com os resultados de Chen (2010), que identificou que as políticas de devolução são importantes para um comportamento de compra positivo do consumidor em relação à loja virtual. A exceção é o S5, que, além de apresentar sua polí- tica superficialmente, estipula um prazo de 24 horas para a aprovação do pedido do cliente e, somente após essa aprovação, agenda a entrega. O S1 oferece um destaque especial à sua política em um quadro do lado direito da página inicial do site. Os $\mathrm{S} 2$ e S8 informam o valor da taxa de entrega por meio do CEP do local no qual o cliente deseja que sua entrega seja realizada. Há a opção de entrega agendada em S2, S4 e S7, sendo cobrados valores diferenciados em relação à entrega regular. $\mathrm{O}$ supermercado S4 é o único que explica detalhadamente, inclusive com exemplos, como o cliente deve considerar o prazo de entrega estipulado pela loja a partir do momento que foi realizado seu pedido de compra, evitando sua insatisfação em relação ao que considera como atraso na entrega. O S3 não disponibiliza nenhuma informação sobre entrega na página principal do site: apenas os clientes que realizam o pedido de compra são informados sobre as regras para entrega ao final do pedido, o que pode desestimular os clientes que visitam o site do supermercado pela primeira vez e buscam esse tipo de informação antes de realizar sua primeira compra.

Outro item analisado foi o que trata das políticas de devolução. Percebe-se que os supermercados estudados possuem comportamentos bastante diferentes a esse respeito. Porém, a maioria oferece serviço de devolução, apresentando regras que estabelecem a possibilidade de fazer troca daqueles produtos que não foram recebidos de forma adequada ou que foram solicitados por engano, evidenciando um maior comprometimento com o cliente. Os supermercados S3, S6 e S7, além de incluírem suas políticas de troca na página principal, o fazem com riqueza de detalhes, dividindo as regras de acordo com trocas, devoluções e cancelamentos para diferentes tipos de produtos, perecíveis e não-perecíveis. O S3 estabelece, ainda, prazos diferenciados de acordo com os motivos que levaram o 
cliente a solicitar a troca do produto. $\mathrm{O}$ S1, por sua vez, informa sua política de devolução dentro do link "informações" que aparece na página principal, fazendo com que o cliente precise investir mais tempo na procura dessa informação. Além disso, as regras são expostas de maneira abrangente, sem especificar os prazos de devolução dos produtos. O S8 apresenta sua política ao final da página, mas também o faz de maneira superficial, disponibilizando ao cliente diferentes canais de comunicação com a loja. Não foram identificadas políticas de devolução em S2 e S5.

A qualidade das fotos dos produtos no ambiente virtual é característica importante, pois o consumidor precisa identificar todas as características destes, de forma a conseguir sanar possíveis dúvidas na realização da compra. Nos supermercados S3, S4, S7 e S8, todos os produtos são divulgados com fotos de boa qualidade, oferecendo ao cliente a opção de ampliar a imagem por meio de zoom. Destes, o S3 é que disponibiliza a maior e melhor imagem do produto ampliada. Apesar disso, não é possível ter acesso por meio das fotos a informações relevantes colocadas nas embalagens dos produtos, o que pode vir a dificultar a decisão do consumidor que necessita disso e levá-lo a preferir as lojas físicas. Os demais supermercados analisados, S1, S2, S5 e S6, apresentam fotos pequenas, de baixa qualidade e sem opção de zoom, dificultando uma compreensão dos itens. O S5, além das características citadas anteriormente, não disponibiliza as fotos de todos os produtos anunciados no site.

O elemento avaliação de produtos possibilita ao consumidor, a partir da opinião e de depoimentos de outros consumidores, formadores de opinião e até mesmo artistas presentes na mídia, conhecer mais sobre a qualidade dos serviços ou produtos adquiridos. Outra forma de o consumidor avaliar os produtos relaciona-se à disponibilidade de amostras, que, no caso dos supermercados virtuais, não é possível. Dessa forma, o item avaliação dos produtos poderia influenciar o comportamento dos consumidores por meio da inserção de opiniões no site. Identificou-se que nenhum dos supermercados analisados explora esse item.

Para análise das ferramentas de auxílio à navegação, observou-se que os supermercados não disponibilizam o mapa do site, com exceção do S7. Todos apresentam uma ferramenta de busca. As barras de navegação são colocadas no topo ou na lateral esquerda dos sites, sinalizando para os clientes as seções nas quais se encontram os produtos procurados, as informações relacionadas ao pedido, as formas de pagamento, as condições de entrega e o fale conosco. A eficiência desse recurso é importante para a satisfação do cliente em relação ao supermercado, pois possibilita que o mesmo se mova rapidamente pelo site e conclua sua compra em um tempo menor (FLOH; MADLBERGER, 2013). Ressalta-se, ainda, que, na parte inferior de todos os sites analisados, também há links que facilitam ao consumidor encontrar informações desejadas. $\mathrm{O}$ destaque quanto a esse item é o S8, que, além de todas as características citadas anteriormente, disponibiliza para o cliente uma barra de navegação diferenciada, com receitas, dicas e recomendações de compras. Outro recurso deste supermercado é o "tour virtual", que descreve as características das atividades desenvolvidas pelos funcionários até os produtos chegarem aos consumidores. Os elementos analisados encontram-se resumidos na Figura 2, exposta a seguir. 


\begin{tabular}{|c|c|c|c|c|c|c|c|c|}
\hline \multirow{2}{*}{ ELEMENTOS } & \multicolumn{8}{|c|}{ SUPERMERCADOS ONLINE } \\
\hline & $\mathbf{S}_{1}$ & $\mathbf{S}_{2}$ & $S_{3}$ & $S_{4}$ & $\mathbf{S}_{5}$ & $\mathbf{S}_{6}$ & $\overline{\mathbf{S}_{7}}$ & $\overline{\mathbf{S}_{8}}$ \\
\hline $\begin{array}{c}\text { Descrição dos } \\
\text { produtos }\end{array}$ & Simples. & Simples. & $\begin{array}{l}\text { Riqueza de } \\
\text { detalhes. }\end{array}$ & Simples. & Simples. & Simples & Simples. & $\begin{array}{l}\text { Riqueza de } \\
\text { detalhes. }\end{array}$ \\
\hline $\begin{array}{c}\text { Descrição das } \\
\text { litas de compras }\end{array}$ & $\begin{array}{l}\text { Seções e } \\
\text { categorias. } \\
\text { Histórico de } \\
\text { compras. }\end{array}$ & $\begin{array}{l}\text { Seções e } \\
\text { categorias. } \\
\text { Histórico de } \\
\text { compras.Listas } \\
\text { prontas. }\end{array}$ & $\begin{array}{l}\text { Seções, } \\
\text { categorias e } \\
\text { preços. Histórico } \\
\text { de compras. }\end{array}$ & $\begin{array}{l}\text { Seçôes c } \\
\text { categorias. } \\
\text { Histórico de } \\
\text { compras. }\end{array}$ & $\begin{array}{l}\text { Seções e } \\
\text { categorias. Não } \\
\text { há histórico de } \\
\text { compras. }\end{array}$ & \begin{tabular}{|l} 
Seções e \\
categorias. \\
Histórico de \\
compras.
\end{tabular} & \begin{tabular}{|l|} 
Seções, \\
categorias, \\
preços, \\
visualização, \\
mais vendidos e \\
similares.
\end{tabular} & $\begin{array}{l}\text { Seções, } \\
\text { categorias, } \\
\text { marcas, } \\
\text { apresentação e } \\
\text { tipo de } \\
\text { embalagem. }\end{array}$ \\
\hline Preços & $\begin{array}{l}\text { Fonte pequena, } \\
\text { sem destaque. }\end{array}$ & $\begin{array}{l}\text { Fonte pequena, } \\
\text { pouco destaque. }\end{array}$ & $\begin{array}{l}\text { Fonte pequena, } \\
\text { sem destaque. }\end{array}$ & $\begin{array}{l}\text { Fonte pequena, } \\
\text { sem destaque. }\end{array}$ & $\begin{array}{l}\text { Fonte pequena, } \\
\text { pouco destaque. }\end{array}$ & \begin{tabular}{|l|}
$\begin{array}{l}\text { Preço com } \\
\text { destaque ao } \\
\text { clicar no produto }\end{array}$ \\
\end{tabular} & $\begin{array}{l}\text { Fonte pequena, } \\
\text { sem destaque }\end{array}$ & $\begin{array}{l}\text { Fonte pequena, } \\
\text { sem destaque. }\end{array}$ \\
\hline $\begin{array}{l}\text { Termos de } \\
\text { Vendas }\end{array}$ & $\begin{array}{l}\text { Regras para } \\
\text { cada forma de } \\
\text { pagamento }\end{array}$ & \begin{tabular}{|l|} 
Detalhes nas \\
regras para cada \\
forma de \\
pagamento
\end{tabular} & $\begin{array}{l}\text { Sem detalhes. } \\
\text { Pagamento em } \\
\text { cartões. }\end{array}$ & $\begin{array}{l}\text { Regras para } \\
\text { cada forma de } \\
\text { pagamento }\end{array}$ & $\begin{array}{l}\text { Sem detalhes. } \\
\text { Pagamento à } \\
\text { vista. }\end{array}$ & \begin{tabular}{|l|} 
Detalhes nas \\
regras para cada \\
forma de \\
pagamento
\end{tabular} & \begin{tabular}{|l|} 
Detalhes nas \\
regras para cada \\
forma de \\
pagamento
\end{tabular} & \begin{tabular}{|l}
$\begin{array}{l}\text { Detalhes nas } \\
\text { regras para cada } \\
\text { forma de } \\
\text { pagamento }\end{array}$ \\
\end{tabular} \\
\hline $\begin{array}{l}\text { Política de } \\
\text { entrega à } \\
\text { domicilio }\end{array}$ & $\begin{array}{l}\text { Destaque no } \\
\text { site }\end{array}$ & $\begin{array}{l}\text { Sem destaque. } \\
\text { Horário } \\
\text { agendado e } \\
\text { regular. } \\
\text { Consulta CEP }\end{array}$ & $\begin{array}{l}\text { Somente ao final } \\
\text { do pedido de } \\
\text { compra. }\end{array}$ & $\begin{array}{l}\text { Entrega } \\
\text { agendada. } \\
\text { Explicação do } \\
\text { tempo de } \\
\text { entrega. }\end{array}$ & $\begin{array}{l}\text { Estipulado um } \\
\text { prazo de 24 } \\
\text { horas para a } \\
\text { aprovação do } \\
\text { pedido c } \\
\text { entrega. } \\
\end{array}$ & $\begin{array}{l}\text { Taxa única. } \\
\text { Entrega em } \\
\text { horários pré- } \\
\text { estabelecidos. }\end{array}$ & \begin{tabular}{|l|} 
O cliente pode \\
agendar o \\
horário \\
especifico para a \\
entrega de suas \\
compras.
\end{tabular} & $\begin{array}{l}\text { Sem destaque. } \\
\text { Consulta CEP. }\end{array}$ \\
\hline $\begin{array}{l}\text { Política de } \\
\text { devolução }\end{array}$ & $\begin{array}{l}\text { Falta de clareza } \\
\text { em relação aos } \\
\text { prazos de troca. }\end{array}$ & $\begin{array}{l}\text { Não foi } \\
\text { localizada. }\end{array}$ & $\begin{array}{l}\text { Detalhada para } \\
\text { desistências e } \\
\text { trocas. } \\
\text { Diferenciada por } \\
\text { tipo de produto e } \\
\text { motivo de troca. }\end{array}$ & $\begin{array}{l}\text { Somente para } \\
\text { pedido } \\
\text { realizado. }\end{array}$ & Não identificada & $\begin{array}{l}\text { Detalhada por } \\
\text { troca, devolução } \\
\text { e cancelamento } \\
\text { de acordo com o } \\
\text { tipo de produto. }\end{array}$ & $\begin{array}{l}\text { Detalhada por } \\
\text { troca, devolução } \\
\text { e cancelamento } \\
\text { de acordo com o } \\
\text { tipo de produto. }\end{array}$ & $\begin{array}{l}\text { Simples, mas } \\
\text { disponibiliza } \\
\text { vários canais de } \\
\text { comunicação }\end{array}$ \\
\hline $\begin{array}{l}\text { Fotos dos } \\
\text { produtos }\end{array}$ & $\begin{array}{l}\text { Baixa } \\
\text { qualidade. Sem } \\
\text { opção de zoom. }\end{array}$ & $\begin{array}{l}\text { Baixa qualidade. } \\
\text { Sem opção de } \\
\text { zoom. }\end{array}$ & \begin{tabular}{|l|} 
Fotos de \\
qualidade. \\
Opção de zoom. \\
Maiores fotos. \\
\end{tabular} & $\begin{array}{l}\text { Fotos de } \\
\text { qualidade. } \\
\text { Opção de zoom. }\end{array}$ & $\begin{array}{l}\text { Fotos de alguns } \\
\text { produtos. Baixa } \\
\text { qualidade. }\end{array}$ & $\begin{array}{l}\text { Baixa qualidade. } \\
\text { Sem opção de } \\
\text { zoom. }\end{array}$ & \begin{tabular}{|l|} 
Fotos de \\
qualidade. \\
Opção de zoom.
\end{tabular} & $\begin{array}{l}\text { Fotos de } \\
\text { qualidade. } \\
\text { Opção de zoom. }\end{array}$ \\
\hline $\begin{array}{c}\text { Avaliação dos } \\
\text { produtos }\end{array}$ & Não disponivel. & Não disponível. & Não disponível. & Não disponivel. & Não disponivel. & Não disponivel. & Não disponível. & Não disponível. \\
\hline $\begin{array}{c}\text { Ferramenta de } \\
\text { auxilio à } \\
\text { navegação }\end{array}$ & $\begin{array}{l}\text { Não há mapa do } \\
\text { site. Opção de } \\
\text { busca. Barras de } \\
\text { navegação. }\end{array}$ & $\begin{array}{l}\text { Não há mapa do } \\
\text { site. Opção de } \\
\text { busca. Barras de } \\
\text { navegação. }\end{array}$ & $\begin{array}{l}\text { Não há mapa do } \\
\text { site. Opção de } \\
\text { busca. Barras de } \\
\text { navegação. }\end{array}$ & $\begin{array}{l}\text { Não há mapa do } \\
\text { site. Opção de } \\
\text { busca. Barras de } \\
\text { navegação. }\end{array}$ & $\begin{array}{l}\text { Não há mapa do } \\
\text { site. Opção de } \\
\text { busca. Barras de } \\
\text { navegação. }\end{array}$ & $\begin{array}{l}\text { Não há mapa do } \\
\text { site. Opção de } \\
\text { busca. Barras de } \\
\text { navegação. }\end{array}$ & $\begin{array}{l}\text { Existe um mapa } \\
\text { no site. Opção } \\
\text { de busca. Barras } \\
\text { de navegação. }\end{array}$ & $\begin{array}{l}\text { Barra de } \\
\text { navegação } \\
\text { diferenciada. } \\
\text { Tour virtual. }\end{array}$ \\
\hline
\end{tabular}

Figura 2 - Resumo dos elementos do ambiente de tarefa altamente relevante Fonte: próprios autores (2013).

$\mathrm{Na}$ segunda parte do roteiro de análise dos estímulos, foram analisadas os elementos do ambiente de tarefa de baixa relevância. Em relação aos elementos como cores, bordas, tipos de fontes e padrões de fundos foi percebido que os supermercados procuram harmonizar as cores dos seus sites às das suas marcas, com predominância do padrão de fundo branco e tonalidades leves, sinalizando um ambiente agradável e que não tira o foco do produto. A importância da escolha adequada desses elementos relacionase à capacidade destes de facilitar ou dificultar para o consumidor realizar a leitura dos elementos que compõem o ambiente de tarefa altamente relevante. Os supermercados analisados apresentam fontes pequenas em seus textos, que, juntamente com as cores do site e o fundo branco, podem tornar cansativa a leitura. O S5, além de apresentar a fonte pequena, apresenta seus textos em um padrão de fundo azul, dificultando a leitura, podendo proporcionar um aspecto não atrativo. No $\mathrm{S} 8$, apesar do predomínio da cor branca, os textos são disponibilizados com uma fonte maior, enquanto no S4, além desta característica, há o uso de diferentes cores de fontes para destacar informações mais importantes nos textos.

Os elementos animação, músicas, sons e entretenimento, que inclui jogos e concursos, têm a vantagem de atrair a atenção do consumidor, mas podem também distraí-lo. Em relação à animação e a músicas e sons, o recurso apresentado pelos supermercados S1, S5, S7 e S8 é um quadro na página inicial com notícias e ofertas de produtos. Os supermercados S2, S4 e S6 apresentam somente ofertas de produtos, enquanto S3 não disponibiliza nenhum tipo de animação. Em relação ao entretenimento, os supermercados não disponibilizam aos consumidores jogos ou outras atividades lúdicas. Apenas S1 apresenta um concurso que dá direito a um cupom raspável. S2 e S6 realizam promoções com a distribuição de brindes a partir da 
compra de produtos indicados. S1, S7 e S8 disponibilizam receitas de diferentes tipos de pratos.

Os supermercados analisados apresentam diversos ícones e mapas de imagem, que incluem fotos dos produtos, links para informações e até mesmo participação em redes sociais. No entanto, todas as vezes que foram acessados no decorrer da coleta de dados, verificou-se que nenhum dos sites apresenta dificuldade no carregamento da página, já que todos os ícones são visualizados imediatamente. Esses recursos permitem ao varejista melhorar sua imagem junto ao consumidor, mas também podem causar insatisfação se provocarem lentidão na navegação e atrasos na conclusão da compra. A rapidez e facilidade no acesso aos dados confirmam os achados de Kim e Stoel (2004), de que a capacidade de transação e o tempo de resposta ao entrar no site são fatores de influência significativa para o comportamento de compra do consumidor. Em relação a outros elementos analisados, a demonstração no site de outras fotos além das dos produtos, como fotos com o objetivo de proporcionar uma decoração, por exemplo, foi identificada apenas em S1, S7 e S8 em pouca quantidade. Além das fotos dos produtos, são demonstradas fotos de receitas de pratos.

Os indicadores de conexões e transações seguras, que possibilitam melhorar a confiança do comprador no varejista, são fornecidos pelos supermercados, com exceção de S1, S5 e S7. A preocupação dos lojistas virtuais de desenvolverem esse elemento corrobora os estudos de Ranganathan e Ganapathy (2002) e Chen (2010), que identificaram que a segurança e privacidade são fatores de forte impacto na intenção de compra dos consumidores. Os supermercados analisados não disponibilizam recursos para contagem de quantas pessoas estão acessando o site naquele momento ou de quantos acessos houve naquele dia, o webcounter. As premiações e os símbolos de filiações profissionais são outros recursos que também servem para aumentar a confiança do comprador em relação ao site. Este elemento está disponível no site de apenas um único supermercado, o S5. Os elementos analisados encontram-se resumidos na Figura 3, exposta a seguir.

\begin{tabular}{|c|c|c|c|c|c|c|c|c|}
\hline \multirow{2}{*}{ ELEMENTOS } & \multicolumn{8}{|c|}{ SUPERMERCADOS ONLINE } \\
\hline & $\mathbf{S}_{1}$ & $\mathbf{S}_{2}$ & $\mathbf{S}_{3}$ & $S_{4}$ & $\mathrm{~S}_{\mathrm{s}}$ & $\mathbf{S}_{6}$ & $\mathbf{S}_{7}$ & $\mathbf{S}_{8}$ \\
\hline Cores & $\begin{array}{l}\text { Tonalidade leve. } \\
\text { Fonte pequena. } \\
\text { Fundo branco. }\end{array}$ & $\begin{array}{l}\text { Tonalidade leve. } \\
\text { Fonte pequena. } \\
\text { Fundo branco. } \\
\text { Harmonia com } \\
\text { marca. }\end{array}$ & $\begin{array}{l}\text { Tonalidade leve. } \\
\text { Fonte pequena. } \\
\text { Fundo branco. } \\
\text { Harmonia com } \\
\text { marca. }\end{array}$ & $\begin{array}{l}\text { Fundo branco. } \\
\text { Harmonia com } \\
\text { marca.Destaque } \\
\text { de informações } \\
\text { importantes }\end{array}$ & $\begin{array}{l}\text { Cores escuras. } \\
\text { Fontes } \\
\text { pequenas. } \\
\text { Fundo azul. }\end{array}$ & $\begin{array}{l}\text { Tonalidade leve. } \\
\text { Fonte pequena. } \\
\text { Fundo branco. } \\
\text { Harmonia com } \\
\text { marca. }\end{array}$ & $\begin{array}{l}\text { Cores fortes. } \\
\text { Fundo branco. }\end{array}$ & $\begin{array}{l}\text { Poucas cores. } \\
\text { Fonte pequena. } \\
\text { Aumento da } \\
\text { fonte nos textos }\end{array}$ \\
\hline Animação & $\begin{array}{l}\text { Quadro com } \\
\text { notícias e } \\
\text { promoções. } \\
\text { Sem música e } \\
\text { sons. } \\
\end{array}$ & $\begin{array}{l}\text { Quadro de } \\
\text { ofertas. Sem } \\
\text { música e sons. }\end{array}$ & Não dispõe. & $\begin{array}{l}\text { Quadro de } \\
\text { ofertas. Sem } \\
\text { música e sons. }\end{array}$ & $\begin{array}{l}\text { Quadro com } \\
\text { notícias e } \\
\text { promoções. Sem } \\
\text { música e sons. }\end{array}$ & $\begin{array}{l}\text { Quadro de } \\
\text { ofertas. Sem } \\
\text { música e sons. }\end{array}$ & $\begin{array}{l}\text { Quadro com } \\
\text { notícias e } \\
\text { promoções. Sem } \\
\text { música e sons. }\end{array}$ & \begin{tabular}{|l} 
Quadro com \\
notícias e \\
promoções. \\
Sem música e \\
sons. \\
\end{tabular} \\
\hline Entretenimento & $\begin{array}{l}\text { Concurso do } \\
\text { cupom raspável. } \\
\text { Receitas. }\end{array}$ & $\begin{array}{l}\text { Promoções com } \\
\text { direito à brindes. }\end{array}$ & Não dispõe. & Não dispõe. & Não dispõe. & $\begin{array}{l}\text { Promoções com } \\
\text { direito à brindes. }\end{array}$ & $\begin{array}{l}\text { Receitas de } \\
\text { pratos. }\end{array}$ & $\begin{array}{l}\text { Receitas de } \\
\text { pratos. }\end{array}$ \\
\hline $\begin{array}{c}\text { Ícones e mapas } \\
\text { de imagem }\end{array}$ & $\begin{array}{l}\text { Não houve } \\
\text { dificuldade no } \\
\text { carregamento } \\
\text { do site. }\end{array}$ & $\begin{array}{l}\text { Não houve } \\
\text { dificuldade no } \\
\text { carregamento do } \\
\text { site. }\end{array}$ & $\begin{array}{l}\text { Não houve } \\
\text { dificuldade no } \\
\text { carregamento do } \\
\text { site. }\end{array}$ & \begin{tabular}{|l|} 
Não houve \\
dificuldade no \\
carregamento \\
do site.
\end{tabular} & $\begin{array}{l}\text { Não houve } \\
\text { dificuldade no } \\
\text { carregamento do } \\
\text { site. }\end{array}$ & $\begin{array}{l}\text { Não houve } \\
\text { dificuldade no } \\
\text { carregamento do } \\
\text { site. }\end{array}$ & $\begin{array}{l}\text { Não houve } \\
\text { dificuldade no } \\
\text { carregamento do } \\
\text { site. }\end{array}$ & \begin{tabular}{|l|} 
Não houve \\
dificuldade no \\
carregamento \\
do site.
\end{tabular} \\
\hline Outas fotos & $\begin{array}{l}\text { Pouca } \\
\text { quantidade. }\end{array}$ & Não & Não & Não & Não & Não & $\begin{array}{l}\text { Pouca } \\
\text { quantidade. }\end{array}$ & $\begin{array}{l}\text { Pouca } \\
\text { quantidade. }\end{array}$ \\
\hline $\begin{array}{c}\text { Indicadores de } \\
\text { conexões e } \\
\text { transações } \\
\text { seguras }\end{array}$ & Não & Sim & Sim & Sim & Não & Sim & Não & Sim \\
\hline Webcounter & $\begin{array}{l}\text { Não é } \\
\text { disponibilizado. }\end{array}$ & $\begin{array}{l}\text { Não é } \\
\text { disponibilizado. }\end{array}$ & $\begin{array}{l}\text { Não é } \\
\text { disponibilizado. }\end{array}$ & $\begin{array}{l}\text { Não é } \\
\text { disponibilizado. }\end{array}$ & $\begin{array}{l}\text { Não é } \\
\text { disponibilizado. }\end{array}$ & $\begin{array}{l}\text { Não é } \\
\text { disponibilizado. }\end{array}$ & $\begin{array}{l}\text { Não é } \\
\text { disponibilizado. }\end{array}$ & $\begin{array}{l}\text { Não é } \\
\text { disponibilizado. }\end{array}$ \\
\hline $\begin{array}{c}\text { Premiações e } \\
\text { símbolos de } \\
\text { filiações } \\
\text { profissionais do } \\
\text { site }\end{array}$ & Não & Não & Não & Não & Sim & Não & Não & Não \\
\hline
\end{tabular}

Figura 3 - Resumo dos elementos do ambiente de tarefa de baixa relevância.

Fonte: próprios autores (2013). 


\section{Considerações finais}

Este estudo buscou analisar, por meio da observação não participante, como são desenvolvidos os estímulos do ambiente da atmosfera de loja virtual, de acordo com os conceitos propostos no modelo de Eroglu et al. (2001). Para tanto, foram selecionados oito supermercados sediados em ambiente virtual, que atuam com base na venda direta e entrega de produtos ao consumidor, todos localizados em território nacional.

Os resultados da análise permitem concluir que os elementos do ambiente de tarefa altamente relevantes são desenvolvidos pelos supermercados analisados de maneira mais criteriosa do que os elementos do ambiente de tarefa com baixa relevância. Isso pode estar relacionado ao fato de que os elementos do ambiente de tarefa altamente relevantes estão mais diretamente ligados à finalização do processo de compra. No entanto, observa-se que os elementos do ambiente de tarefa com baixa relevância, embora não tenham relação direta com o fechamento da compra, podem representar um importante recurso para o varejista on-line desenvolver diferenciais em relação à concorrência, tanto física como virtual. Também possibilitam criar uma imagem agradável do site, desenvolvendo no consumidor situações que provoquem sua satisfação e despertem seu interesse para sempre preferir realizar suas compras nesse ambiente. Embora influenciem de maneira diferente o comportamento de compra do consumidor, ambos os elementos que compõem o ambiente da atmosfera da loja virtual influenciam positivamente esse comportamento, conforme apontado por pesquisas anteriores (CHEN, 2010; GRIFFITH, 2005; FARIAS, 2005; MENON; KAHN, 2002; RANGANATHAN; GANAPATHY, 2002).

No tocante ao conjunto de elementos que compõem cada ambiente de tarefa, sugere-se que, além da descrição das características dos produtos, o consumidor possa ler as informações contidas nas embalagens por meio de imagens de boa qualidade, com zoom e movimentos, principalmente em relação a produtos recém-lançados no mercado, sobre os quais não tem conhecimento. A boa apresentação dos produtos pode influenciar significativamente a experiência de compra, tornando-a satisfatória e, consequentemente, gerando comportamentos de compra mais positivos (MENON, KAHN, 2002; CHEN, 2010).

Em relação à lista de compras, atualmente disponibilizada com um grupo de produtos divididos em seções colocadas na lateral esquerda ou no topo dos sites, sugere-se que esta seja apresentada de forma mais lúdica a fim de proporcionar ao consumidor um verdadeiro tour virtual, fazendo com que ele literalmente ingresse em um supermercado desenhado na tela de seu computador e navegue pelas seções de seu interesse a partir das sinalizações encontradas. Os elementos preços, termos de venda e políticas de entrega em domicílio e devolução necessitam de maior destaque e detalhamento, visto que essas informações são imprescindíveis para o fechamento da compra e também para resguardar os supermercados de possíveis problemas futuros junto aos consumidores. O elemento avaliação dos produtos não é disponibilizado pelos supermercados analisados, mas pode representar um fator de decisão para o comprador, principalmente se este faz a compra pela primeira vez.

Os elementos animação e entretenimento quase não são disponibilizados pelos supermercados, possivelmente porque há o risco de tornarem a navegação mais lenta ou porque os clientes preferem realizar suas compras de maneira mais rápida e eficiente, sem investir tempo em outras questões. Conforme afirmam Floh e Madlberger (2013), a eficácia da navegação no site influencia positivamente o comportamento do consumidor. Assim sendo, sugere-se aos varejistas buscarem essa 
informação junto aos clientes por meio de pesquisas, a fim de identificarem se preferem um site sem esses recursos ou com uma atmosfera mais animada.

O webcounter, as premiações, os símbolos de filiações profissionais do site e outros elementos pouco disponibilizados servem como um indicador da qualidade e aumentam a confiabilidade do consumidor no varejista, essencialmente para aqueles que não possuem loja física. Chen (2010) sugere que a confiança do consumidor em relação ao website é importante para o desenvolvimento de uma relação de longo prazo.

Do ponto de vista acadêmico, este estudo traz contribuições relevantes ao possibilitar um melhor entendimento de como são desenvolvidos os estímulos do ambiente da loja virtual, visto que eles têm a função de influenciar o estado interno dos compradores e provocar respostas de aproximação ou afastamento. Além disso, permitiu entender melhor de que maneira o varejo está evoluindo por meio da internet para aproximar-se do consumidor, oferecendo uma opção a mais para a realização de suas compras, com conforto, rapidez e comodidade. Se, por um lado, diferenciar-se do concorrente no ambiente virtual é mais difícil, sem poder fazer uso dos recursos das lojas físicas, como merchandising, luzes, sinalização, cores e cheiros (MUMMALANENI, 2005), por outro lado, o ambiental virtual oferece flexibilidade no tempo e espaço aos consumidores (EROGLU et al., 2001).

Esta pesquisa apresenta limitações que podem ser superadas por outras realizadas no futuro. Conforme indicado na metodologia, foram analisados oito supermercados virtuais, motivo pelo qual os resultados devem ser considerados sob a perspectiva destas empresas, não devendo serem feitas generalizações. Sugere-se que novas observações sejam efetuadas com um número maior de unidades analisadas, confirmando ou não os achados desta pesquisa. Outra limitação refere-se ao fator geográfico, que impossibilitou os pesquisadores de concluírem os pedidos de compra porque não estavam localizados na área de abrangência de entrega dos supermercados. Essa foi a razão pela qual não se pôde participar efetivamente do processo de compra.

Além disso, o estudo ficou restrito aos supermercados virtuais. Outros estudos poderiam ser realizados com o intuito de verificar como esses elementos são desenvolvidos por outros tipos de lojas virtuais, permitindo saber se o tipo de loja implica o desenvolvimento de alguns elementos em detrimento de outros. Apenas uma parte do modelo proposto por Eroglu et al. (2001), os estímulos do ambiente, foi analisada nesta pesquisa. Desse modo, as demais partes do modelo, estado interno do organismo e resposta do comprador, poderiam ser analisadas em estudos futuros. Outro estudo poderia, ainda, analisar a opinião dos consumidores em relação aos estímulos do ambiente, verificando de que forma eles influenciam seu comportamento de compra. Outra sugestão refere-se à realização de estudos que aprofundem de que maneira os fatores sociais, que também compõem a atmosfera de loja, podem ser desenvolvidos dentro do ambiente virtual.

Em seu conjunto, os resultados apontam que alguns elementos dos ambientes estudados poderiam ser desenvolvidos de maneira mais eficaz pelos supermercados, contribuindo para melhorar o nível de resposta dos clientes. A construção de um site de vendas que transmita confiança e possibilite interatividade, por meio do desenvolvimento dos elementos do ambiente que estimulam o comportamento dos consumidores, pode proporcionar uma experiência de compra satisfatória. O comportamento de compra positivo, resultante da aproximação do comprador, poderá ocorrer com maior frequência nos supermercados virtuais a partir do momento em que o consumidor se sentir estimulado a realizar suas compras nesse ambiente. 


\section{Referências}

1. ALBA, J.; et al. Interactive home shopping: consumer, retailer, and manufacturer incentives to participate in eletronic marketplaces. Journal of Marketing, v. 61, n. 3, p. 38-53, jul. 1997.

2. ASSOCIAÇÃO BRASILEIRA DE SUPERMERCADOS. Ranking Abras 2013. Revista Super Hiper, n. 442, abr. 2013. Disponível em: <http://abrasnet.com.br/edicoes-anteriores/Main. php? MagID=7\&MagNo=130>. Acesso 04 dez. 2013.

3. BACKER, J.; PARASURAMAN, A.; GREWAL, D.; VOSS, G. B. The influence of multiple store environment cues on perceived merchandise value and patronage intentions. Journal of Retailing, v. 66, n. 2, p. 120-141, 2002.

4. BITNER, M. J. Evaluating servisse encounters: the effects of physical surroundings and employee responses. Journal of Marketing, v. 54, p. 69-82, Apr. 1990.

5.

Servicescapes: the impacto $\mathrm{f}$ physical surroundings on customers and employees. Journal of Marketing, v. 56, n. 2, p. 57-71, Apr. 1992.

6. BURKER, R. R.; HARLAM, B. A.; KAHN, B. E.; LODISH, L. M. Comparing dynamics consumer choice in real and computer simulated environments. Journal of Consumer Research, v. 19, n. 1, p. 71-82, jun. 1992.

7. CARVALHO, J. L. F. S.; MOTTA, P. C. Experiências em cenários temáticos de serviços. RAE - Revista de Administração de Empresas, v. 42, n. 2, p. 54-65, abr.jun. 2002.

8. CHEN, Y. H.; HSU, I-C.; LIN, C.C. Website atributes thar increase consumer purchase intention: a conjoint analysis. Journal of Business Research, v. 63, p. 1007-1014, 2010.

9. COSTA, F. C. X.; LARÁN, J. A. In- fluência do ambiente de loja e o comportamento de compra por impulso: a visão dos clientes de lojas virtuais. Revista de Administração, v. 41, n. 1, p. 96-106, jan./fev./mar. 2006.

10. CUTIERI, P. G.; DONAIRE, D. Considerações sobre o supermercado virtual: um estudo sobre o comércio eletrônico de alimentos e o perfil do seu consumidor. In: EnANPAD, 24., 2000, Florianópolis. Anais... Florianópolis: ANPAD, 2000. 1 CD-ROM.

11. DAILEY, L. Navigational web atmospherics: explaining the influence of restrictive navigation cues. Journal of Business Research, p. 57, n. 7, p. 795803, 2004.

12. DONAVAN, R. J.; ROSSITER, J. R.; MARCOOLYN, G.; NESDALE, A. Store atmosphere and purchasing behavior. Journal of Retailing, v. 70, n. 3, p. 283-294, 1994.

13. EROGLU, S.A.; MACHLEIT, K. A.; DAVIS, L. M. Atmospheric qualities of online retailing: a conceptual model and implications. Journal of Business Research, v. 54, p. 177-184, 2001.

14. ESPINOZA, F.; D’ANGELO, A. C.; LIBERALI, G. A influência da atmosfera de varejo sobre os consumidores. RAUSP - Revista de Administração da Universidade de São Paulo, v. 40, n. 2, p. 109-122, abr./maio/jun. 2005.

15. EVANSCHITZKY, H.; IYER, G. R.; HESSE, J.; AHLERT, D. E-satisfaction: a re-examination. Journal of Retailing, v. 80, n. 3, p. 239-247, 2004.

16. FARIAS, S. A. Atmosfera de loja online: o impacto do ambiente virtual na satisfação do consumidor. In: EnANPAD, 29., 2005, Brasília. Anais... Brasília: ANPAD, 2005. 1 CD-ROM.

17. FEIJÓ, F. R.; BOTELHO, D. Efeito dos fatores de merchandising nas vendas do varejo. RAE - Revista de Administração de Empresas, v. 52, n. 6, p. 628-642, nov./dez. 2012. 
18. FLOH, A.; MADLBERGER, M. The role of atmospheric cues in online impulse-buying behavior. Eletronic Commerce Research and Applications, v. 12, p. 425-439, 2013.

19. GALHANONE, R. F.; MARQUES, J. A.; MAZZON, J. A.; TOLEDO, G. L. O luxo ao alcance do mouse: transferindo a atmosfera das lojas de varejo de luxo tradicionais para a internet. In: EnANPAD, 35., 2011, Rio de Janeiro. Anais... Rio de Janeiro: ANPAD, 2011. 1 CD-ROM.

20. GODOY, A. S. Pesquisa qualitativa: tipos fundamentais. Revista de Administração de Empresas, v. 35, n. 3, p. 20-29, mai.jun. 1995.

21. GRAEML, A. R.; GRAEML, K. S.; STEIL, A. V. Comércio eletrônico: o supermercado virtual na percepção do cliente. In: SIMPÓSIO DE ADMINISTRAÇÃO DA PRODUÇÃO, LOGÍSTICA E OPERAÇÕES INDUSTRIAIS, 3., 2000, São Paulo. Anais... São Paulo: EASESP-FGV, 2000. Disponível em: $<$ http://www.dainf.ct.utfpr.edu.br/ graeml/publica/artigos/download/SIMPOI2000_ComercioEletronico.pdf $>$. Acesso em: 15 jun. 2013.

22. HIJJAR, M. F. Oportunidades no setor supermercadista virtual: uma análise sobre a perspectiva do consumidor. CEL - Centro de Estudos em Logística - COPPEAD/UFRJ. 2006. Disponível em: < http://www.ilos.com. br/web/index.php?option=com_content\&task=view\&id=1109\&Itemid=7>. Acesso em: 15 dez. 2013.

23. HOFFMAN, D. L.; NOVAK, T. P. Marketing in hypermedia computermediated environments: conceptual foundations. Journal of Marketing, v. 60, n. 3, p. 50-68, jul. 1996.

24. KIM, S.; STOEL, L. Apparel retailers: website quality dimensions and satisfaction. Journal of Retailing and Consumer Services, v. 11, p. 109-117, 2004.
25. KOTLER, P. Atmospherics as a marketing tool. Journal of Retailing, v. 49, p. 48-64, winter, 1973.

26. KOVACS, M. H.; BARBOSA, M. de L. de A. A atmosfera do e-tailing, riscos percebidos e a satisfação do consumidor: a proposição de um esquema teórico para e-commerce com base no modelo S-O-R. In: EnANPAD, 29., 2005, Brasília. Anais... Brasília: ANPAD, 2005. 1 CD-ROM.

27. LERNER, M. G. Supermercado virtual: avaliação de qualidade dos serviços de e-commerce dos supermercados no Rio de Janeiro. 2003. 132 p. Dissertação (Mestrado em Administração) - Instituto COPPEAD de Administração, Universidade Federal do Rio de Janeiro, Rio de Janeiro, 2003.

28. LIU, C.; ARNETT, K. P. Exploring the factors associated with web site success in the context of electronic commerce. Information \& Management, v. 38, p. 23-33, 2000.

29. LOHSE, G. L.; SPILLER, P. Internet retail store design: how the user interface influences traffic and sales. J ComputMediat Commun, v. 5, n. 2, 1999. Disponível em: $<$ http://onlinelibrary.wiley. com/doi/10.1111/j.1083-6101.1999. tb00339.x/full>. Acesso em: 3 dez. 2013.

30. MANGANARI, E. E.; SIOMKOS, G. J.; VRECHOPOULOS, A. P. Store atmosphere in web retailing. European Journal of Marketing, v. 43, n. 9/10, p. 1140-1153, 2009.

31. MCKINNEY, L. N. Creating a satisfying internet shopping experience via atmospheric variables. International Journal of Consumer Studies, v. 28, n. 3, p. 268-283, 2004.

32. MENON, S.; KAHN, B.. Cross-category effects of induced arousal and pleasure in the internet shopping experience. Journal of Retailing, v. 78, p. 31-40, 2002.

33. MOREIRA, A. B.. O processo de 
decisão de compra em supermercados on-line: uma pesquisa qualitativa com Zona Sul Atende. 2008. 134 p. Dissertação (Mestrado em Administração) - Pontifícia Universidade Católica, Rio de Janeiro, 2008.

34. MUMMALANENI, V. An empirical investigation of web site characteristics, consumer emotional states and online shopping behaviors. Journal of Business Research, v. 58, p. 526-532, 2005.

35. MURPHY, A. J. Grounding the virtual: the material effects of electronic grocery shopping. Geoforum, v. 38, p. 941-953, 2007.

36. RANGANATHAN, C.; GANAPATHY, S. Key dimensions of businessto-consumer web sites. Information \& Management, v. 39, p. 457-465, 2002.

37. SAMPAIO, C. H.; SANZI, G.; SLONGO, L. A.; PERIN, M. G. Fatores visuais de design e sua influência nos valores de compra do consumidor. RAE - Revista de Administração de Empresas, n. 4, v. 49, p. 373-386, out./ dez. 2009.

38. SZYMANSKI, D. M.; HISE, R. T. E-satisfaction: an initial examination. Journal of Retailing, v. 76, n. 3, p. 309-322, 2000.

39. TURLEY, L. W.; MILLIMAN, R. E. Atmospheric effects on shopping behavior: a review of the experimental evidence. Journal of Business Research, v. 49, p. 193-211, 2000.

40. WU, W. Y.; LEE, C. L.; FU, C.-S.; WANG, H. C. How can online store layout design and atmosphere influence consumer shopping intention on a website? International Journal of Retail \& Distribution Management, v. 42, n. 1, p. 4-24, 2014. 